\title{
Survival and Determinants of Mortality in Adult HIV/AIDS Patients Initiating Antiretroviral Therapy in Somali Region, Eastern Ethiopia
}

\section{Bereket Damtew ${ }^{1 *}$, Bezatu Mengistie ${ }^{2}$ and Tadesse Alemayehu²}

${ }^{1}$ Department of Epidemiology and Biostatistics, College of Health and Medical Sciences, Haramaya University, Ethiopia

${ }^{2}$ Department of Public Health, College of Health and Medical Sciences, Haramaya University, Ethiopia

\begin{abstract}
Background: Studies have shown high initial mortality in Antiretroviral Therapy (ART) programs from resource-limited settings. However, there is dearth of evidence on treatment outcomes and associated determinant factors in public hospitals. Therefore, the objective of this study is to assess survival and identify predictors of death in adult HIV-infected patients initiating ART at a public hospital in Eastern Ethiopia.
\end{abstract}

Methods: A retrospective cohort study was conducted by reviewing baseline and follow-up records of patients who started ART between December 1, 2007 and December 31, 2011 at Kharamara hospital. Time to death was the main outcome measure. KaplanMeier models were used to estimate mortality and Cox proportional hazards models to identify predictors of mortality.

Results: A total of 784 patients (58.4\% females) were followed for a median of 60 months. There were $87(11.1 \%)$ deaths yielding an overall mortality rate of $5.15 / 100 \mathrm{PYO}(95 \% \mathrm{Cl}: 4.73-6.37)$. The estimated mortality was $8.4 \%, 9.8 \%, 11.3 \%, 12.7 \%$ and $14.1 \%$ at 6 , $12,24,36$ and 48 month respectively. The independent predictors of death were single marital status (AHR: 2.31; 95\%Cl: $1.18-4.50)$, a bedridden functional status (AHR: $5.91 ; 95 \% \mathrm{Cl}: 2.87-12.16$ ), advanced WHO stage (AHR: 7.36 ; $95 \% \mathrm{Cl}: 3.17-17.12$ ), Body Mass Index

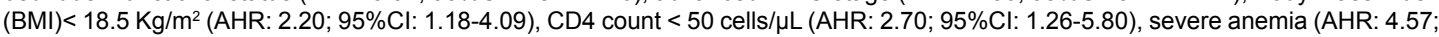
95\% Cl: 2.30-9.10), and Tuberculosis (TB) co-infection (AHR: 2.30; 95\%Cl: 1.28-4.11).

Conclusion: Improved survival was observed in patients taking ART in Somali region of Ethiopia. The risk for death was higher in patients with advanced WHO stage, low CD4 count, low Hgb, low BMI, and concomitant TB infection. Intensive case management is recommended for patients with the prognostic factors. Optimal immunologic and weight recoveries in the first 6 months suggest increased effort to retain patients in care at this period.

Keywords: HIV/AIDS; Mortality; HAART; Survival; Predictors of death; Antiretroviral therapy; Ethiopia

\section{Introduction}

According to the 2012 UNAIDS report, there are an estimated 34 million People Living with HIV (PLHIV) worldwide, Sub-Saharan Africa (SSA) accounting for $69 \%$, with nearly 1 in every 20 adults (4.9\%) living with HIV; around 1.7 million people died from AIDS-related causes worldwide, $70 \%$ occurred in SSA [1]. Ethiopia is one of the hardest hit sub-Saharan African countries by the HIV pandemic. By the end of 2012, there were 759,268 people living with HIV; 41,444 deaths from AIDS-related causes and 20,158 new HIV infections [2]. For 2007, the estimated life expectancy was 52.5 years, with 3.9 years lost to AIDS [3].

In January 2005, the FDRE Ministry of Health $(\mathrm{MoH})$ launched the free ART rollout program. By the end of 2011 there were 249,174 patients on treatment, making the ART coverage for adult population of PLHIV 86\% [4]. The introduction of HAART witnessed a decrease in AIDS-defining opportunistic infections, a decline in AIDS related mortalities, and improved survival of PLHIV. Despite increased availability of ARV and promising efficacy reported from ART programs in resource-limited settings, mortality has been high particularly the first few months after initiating ART $[5,6]$.

Reporting treatment outcomes of patients enrolled in ART programs is important to demonstrate program effectiveness and justify continued funding, while assessment of factors associated with outcomes can help to identify opportunities for program improvement [7]. Few studies have reported baseline socio-demographic and clinical factors in predicting survival after ART initiation [8-10]. However, there are no studies describing mortality on ART and its associated factors over longer follow up periods. Therefore, this study determines factors associated with survival and progressive immunologic and weight changes among adult PLHIV receiving ART in Somali region, Ethiopia.

\section{Methods}

\section{Study setting}

The study was conducted at Kharamara hospital, in Jijiga town from March to May 2013. Jijiga, the administrative capital of Somali region, is located $614 \mathrm{~km}$ to the east of Addis Ababa, Ethiopia's capital. The hospital provides general outpatient and inpatient services, surgical and obstetric emergency, and regional referral hospital for ophthalmologic service. In the comprehensive HIV care and treatment service at the hospital, there are 9,208 patients enrolled, of which 1,501 ever-started ART, and 1,432 currently on ART.

\section{Study design}

A retrospective cohort study was conducted to assess survival and determinants of mortality among PLHIV receiving antiretroviral therapy. A total of 784 PLHIV aged $\geq 15$ years, initiating ART at Kharamara hospital between December 1, 2007 and December 31, 2011 were included in the study. The independent variables were sociodemographic characteristics, baseline clinical, laboratory and ART information. The main outcome measure in the study was follow-up

*Corresponding author: Bereket Damtew, Department of Epidemiology and Biostatistics, College of Health and Medical Sciences, Haramaya University, P.O. Box 1570, Harar, Ethiopia, Tel: 251911730383; E-mail: bekiofdu@gmail.com

Received May 17, 2014; Accepted July 24, 2014; Published July 30, 2014

Citation: Damtew B, Mengistie B, Alemayehu T (2014) Survival and Determinants of Mortality in Adult HIVIAIDS Patients Initiating Antiretroviral Therapy in Somali Region, Eastern Ethiopia. J AIDS Clin Res 5: 327. doi:10.4172/2155-6113.1000327

Copyright: (C) 2014 Damtew B, et al. This is an open-access article distributed unde the terms of the Creative Commons Attribution License, which permits unrestricted use, distribution, and reproduction in any medium, provided the original author and source are credited. 
time till death. The second outcome measures were median changes in CD4 count and weight.

\section{Participants}

The source population was adult HIV/AIDS patients who started ARV and were on follow up at the ART clinic during the study period. Patients who initiated treatment outside Kharamara hospital, and women who were pregnant and lactating mothers on Prevention of Mother to Child Transmission (PMTCT) were excluded. The sample size was determined by taking the mortality rates in two groups of PLHIV on ART based on their WHO clinical stage as exposure status. The mortality rate among exposed (WHO stage IV) is $0.3 \%$ and among non-exposed (WHO stage II-III), 0.1\% [10]. The study participants were randomly selected using patients' unique identification number and were retrospectively followed for additional 60 months until December 31, 2012.

\section{Data collection and quality control}

To compile the required information a data collection form was developed from the national ART intake and follow-up forms. The data were collected by reviewing pre-ART register, ART intake form, laboratory request form, monthly cohort form, and follow up form. The most recent laboratory results before starting ART were used as a baseline value. If there were no pre-treatment laboratory tests, results obtained within one month of ART initiation were used as baseline. If two results were obtained within a month, their mean would be used.

The data was collected by two experienced ART nurses who were trained on comprehensive HIV care and who are working in the ART clinic at Kharamara hospital. A supervisor supervised the data collection process. The investigator oversaw the overall process. All completed data collection forms were examined for completeness, consistency and clarity during data management, storage, and analysis.

\section{Study variable and measurements}

The main outcome variable in this study was death from all causes obtained from patients' medical records in the hospital, and registrations at the ART clinic reported by adherence supporters. Patients were censored on the date of any one of the following events, whichever occurred first: if lost to follow-up, if transferred to another health facility, or if alive at the end of follow up. Additional home visits and phone calls were made by two adherence supporters to confirm outcome status of lost to follow-up patients at the time of censoring.

All HIV-positive persons were routinely screened for $\mathrm{TB}$ at enrolment, and during each follow-up visit. The national TB/HIV guidelines recommend administration of INH Preventive Therapy (IPT) to HIV-infected persons after exclusion of active TB. The recommended dose of INH for adults is $300 \mathrm{mg} /$ day for duration of six months [11]. Diagnosis of active TB infection in HIV-positive patients was made based on microscopic results for Acid-Fast Bacilli (AFB) [12] as: TB-positive (at least 1 initial sputum smear positive for AFB by direct microscopy, or 1 initial sputum smear positive for AFB by concentrated method) and TB-negative (3 initial smears negative for AFB).

Adherence to ART was evaluated by the percentage of missed doses documented by the ART physician [13], and was ranked as good (if $<5 \%$ ( $<2$ doses of 30 doses or $<3$ dose of 60 doses), fair (if between $5-15 \%$ (3-5 doses of 30 doses or 3-9 doses of 60 doses) or poor (if $>15 \%$ ( $>6$ doses of 30 doses or $>9$ dose of 60 dose) as documented by ART physician.Body mass index (BMI) was used to assess patients' nutritional status. Established cutoff values for BMI were used [14]: normal $\left(B M I \geq 18.5 \mathrm{~kg} / \mathrm{m}^{2}\right)$, and malnutrition $\left(B M I<18.5 \mathrm{~kg} / \mathrm{m}^{2}\right)$. Anemia was defined as a hemoglobin level of $<12 \mathrm{~g} / \mathrm{dL}$ for women and $<13 \mathrm{~g} / \mathrm{dL}$ for men [15], and was classified as mild (hemoglobin 10-11.9 $\mathrm{g} / \mathrm{dL}$ for women and $10-12.9 \mathrm{~g} / \mathrm{dL}$ for men), moderate (hemoglobin $8-9.9 \mathrm{~g} / \mathrm{dL}$ ) or severe (hemoglobin $<8 \mathrm{~g} / \mathrm{dL}$ ).

\section{Data analysis}

Data exploration was carried out to check for any inconsistencies, coding error, out of range, and missing values and appropriate corrections were made. Descriptive analyses of the continuous and categorical data describing the cohort's characteristics at baseline and during followup were made. The outcomes of each patient were dichotomized into censored or dead. Kaplan-Meier model was used to assess survival functions stratified by baseline and follow up variables, and the log-rank test was used to assess statistical difference among groups (for equality of survival distributions). Multicollinearity was excluded using Spearman's correlation coefficient with a cutoff at 0.5 . Cox-proportional hazards model was used to identify prognostic factors of death and variables significant at $\mathrm{P}<0.25$ level in the bivariate analysis were included in the final multivariable model. All analyses were conducted using SPSS version 16.0 for windows (SPSS Inc., Chicago, IL, USA).

\section{Results}

The study cohort included 784 patients with a mean age of 34 $(\mathrm{SD} \pm 10)$. Out of the total study population, 485 (58.4\%) were females.

\begin{tabular}{|c|c|c|c|c|}
\hline Variables & Total $(\mathrm{N}, \%)$ & Dead (N, \%) & Active (N, \%) & Log-rank $P$ \\
\hline \multicolumn{4}{|l|}{ Sex } & \multirow{3}{*}{0.019} \\
\hline Male & $326(41.6 \%)$ & $46(52.9 \%)$ & $280(40.2 \%)$ & \\
\hline Female & $458(58.4 \%)$ & $41(47.1 \%)$ & $417(59.8 \%)$ & \\
\hline \multicolumn{4}{|l|}{ Age category } & \multirow{5}{*}{0.249} \\
\hline $15-24$ & $108(13.8 \%)$ & $6(6.9 \%)$ & $102(14.6 \%)$ & \\
\hline $25-34$ & $327(41.7 \%)$ & $41(47.1 \%)$ & $102(14.6 \%)$ & \\
\hline $35-44$ & $229(29.2 \%)$ & $25(28.7 \%)$ & $204(29.3 \%)$ & \\
\hline $45+$ & $120(15.3 \%)$ & $15(17.2 \%)$ & $105(15.1 \%)$ & \\
\hline \multicolumn{4}{|l|}{ Religion } & \multirow{4}{*}{0.714} \\
\hline Muslim & $319(40.7 \%)$ & $35(11.0 \%)$ & $284(89.0 \%)$ & \\
\hline Orthodox & $438(55.9 \%)$ & $50(11.4 \%)$ & $388(88.6 \%)$ & \\
\hline Protestant & $27(3.4 \%)$ & $2(7.4 \%)$ & $25(92.6 \%)$ & \\
\hline \multicolumn{4}{|l|}{ Marital status } & \multirow{6}{*}{0.002} \\
\hline Married & $325(41.5 \%)$ & $27(31.0 \%)$ & $298(42.8 \%)$ & \\
\hline Single & $115(14.7 \%)$ & $24(27.6 \%)$ & $91(13.1 \%)$ & \\
\hline Separated & $27(3.4 \%)$ & $1(1.1 \%)$ & $26(3.7 \%)$ & \\
\hline Divorced & $226(28.8 \%)$ & $26(29.9 \%)$ & $200(28.7 \%)$ & \\
\hline Widowed & $91(11.6 \%)$ & $9(10.3 \%)$ & $82(11.8 \%)$ & \\
\hline \multicolumn{4}{|c|}{ Educational status } & \multirow{5}{*}{0.000} \\
\hline No education & $297(37.9 \%)$ & $48(55.2 \%)$ & $249(35.7 \%)$ & \\
\hline Primary & $217(27.7 \%)$ & $27(31.0 \%)$ & $190(27.3 \%)$ & \\
\hline Secondary & $207(26.4 \%)$ & $10(11.5 \%)$ & $197(28.3 \%)$ & \\
\hline College/Above & $63(8.0 \%)$ & $2(2.3 \%)$ & $61(8.8 \%)$ & \\
\hline \multicolumn{4}{|l|}{$\begin{array}{l}\text { Dependent } \\
\text { children }\end{array}$} & \multirow{3}{*}{0.889} \\
\hline Yes & $455(58.0 \%)$ & $52(59.8 \%)$ & $403(57.8 \%)$ & \\
\hline No & $329(42.0 \%)$ & $35(40.2 \%)$ & $294(42.2 \%)$ & \\
\hline \multicolumn{4}{|l|}{ ART Adherence ${ }^{*}$} & \multirow{4}{*}{0.000} \\
\hline Good & $431(55.0 \%)$ & $36(41.4 \%)$ & $395(56.7 \%)$ & \\
\hline Fair & $431(55.0 \%)$ & $20(23.0 \%)$ & $157(22.5 \%)$ & \\
\hline Poor & $176(22.4 \%)$ & $31(35.6 \%)$ & $145(20.8 \%)$ & \\
\hline
\end{tabular}

Table 1: Socio-demographic characteristics of adult PLHIV receiving ART in Somali region, Ethiopia [N=784], May 2013. 
Three hundred twenty five (41.5\%) were married and 455 (58\%) had dependent children at home. Four hundred eighty seven $(62.1 \%)$ had at least completed primary education, and 359 (45.8\%) had no occupation. The majority 431 (55\%) had good ART adherence (Table 1).

At the time of ART initiation, 455 (58.0\%) were in WHO clinical stage III\&IV and $242(30.9 \%)$ had an ambulatory functional status. Among the study participants, $449(57.3 \%)$ had a $\mathrm{BMI}<18.5 \mathrm{Kg} / \mathrm{m}^{2}$ and 311 (39.7\%) developed active TB infection. At ART initiation time, 221 (28.2\%) were receiving $\mathrm{d} 4 \mathrm{~T} / 3 \mathrm{TC} / \mathrm{NVP}$ ART regimen. With regard to chemoprophylaxis, the majority $658(83.9 \%)$ were given cotrimoxazole and only $61(7.8 \%)$ received Isoniazid (INH) preventive therapies. The mean (IQR) weight, CD4 count and hemoglobin of the cohort were $50 \mathrm{~kg}$ (44-56), 150 cells $/ \mu \mathrm{L}(102-196)$ and $11.4 \mathrm{~g} / \mathrm{dL}(10-13)$ respectively (Table 2).

\section{Follow up}

A total of $87(11.1 \%)$ patients died during the five year followup period, with majority of deaths $49(56.3 \%)$ occurring in the first 3 months (HR: 0.022). One hundred fifty seven (20.0\%) patients were transferred to other facility and 193 (24.6\%) were lost-to-follow up. The remaining 344 (43.9\%) were active until the last censoring date. The median survival time for event (death) was 20.7 months (IQR, 17.522.6). The overall mortality rate in the cohort during the 1,608 person-

\begin{tabular}{|c|c|c|c|c|}
\hline Variables & Total (N, \%) & Dead (N, \%) & Active (N, \%) & Log-rank $P$ \\
\hline \multicolumn{4}{|l|}{ Functional status } & \multirow{4}{*}{0.000} \\
\hline Working & $434(55.4 \%)$ & $12(13.8 \%)$ & $422(60.5 \%)$ & \\
\hline Ambulatory & $242(30.9 \%)$ & $37(42.5 \%)$ & $205(29.4 \%)$ & \\
\hline Bedridden & $108(13.8 \%)$ & $38(43.7 \%)$ & $70(10.0 \%)$ & \\
\hline \multicolumn{4}{|l|}{ WHO staging } & \multirow{4}{*}{0.000} \\
\hline Stage I \& II & $329(42.0 \%)$ & $10(11.5 \%)$ & $319(45.8 \%)$ & \\
\hline Stage III & $327(41.7 \%)$ & $38(43.7 \%)$ & $289(41.5 \%)$ & \\
\hline Stage IV & $128(16.3 \%)$ & $39(44.8 \%)$ & $89(12.8 \%)$ & \\
\hline \multicolumn{4}{|l|}{ BMI for age } & \multirow{3}{*}{0.000} \\
\hline$\geq 18.5 \mathrm{Kg} / \mathrm{m}^{2}$ & $335(42.7 \%)$ & $23(26.4 \%)$ & $312(44.8 \%)$ & \\
\hline$<18.5 \mathrm{Kg} / \mathrm{m}^{2}$ & $449(57.3 \%)$ & $64(73.6 \%)$ & $385(55.2 \%)$ & \\
\hline \multicolumn{4}{|l|}{ ART regimen } & \multirow{7}{*}{0.429} \\
\hline d4T/3TC/NVP & $221(28.2 \%)$ & $25(28.7 \%)$ & $196(28.1 \%)$ & \\
\hline d4T/3TC/EFV & $78(9.9 \%)$ & $7(8.0 \%)$ & $71(10.2 \%)$ & \\
\hline AZT/3TC/NVP & $202(25.8 \%)$ & $25(28.7 \%)$ & $177(25.4 \%)$ & \\
\hline AZT/3TC/EFV & $50(6.4 \%)$ & $5(5.7 \%)$ & $45(6.5 \%)$ & \\
\hline TDF/3TC/EFV & $118(15.1 \%)$ & $10(11.5 \%)$ & $108(15.5 \%)$ & \\
\hline TDF/3TC/NVP & $115(14.7 \%)$ & $15(17.2 \%)$ & $100(14.3 \%)$ & \\
\hline \multicolumn{4}{|l|}{ Cotrimoxazole } & \multirow{3}{*}{0.032} \\
\hline Given & $658(83.9 \%)$ & $66(75.9 \%)$ & $592(84.9 \%)$ & \\
\hline Not given & $126(16.1 \%)$ & $21(24.1 \%)$ & $105(15.1 \%)$ & \\
\hline \multicolumn{4}{|l|}{ INH Given } & \multirow{3}{*}{0.000} \\
\hline Given & $61(7.8 \%)$ & $20(23.0 \%)$ & $41(5.9 \%)$ & \\
\hline Not given & $723(92.2 \%)$ & $67(77.0 \%)$ & $656(98.3 \%)$ & \\
\hline \multicolumn{4}{|l|}{ TB co-infected } & \multirow{3}{*}{0.015} \\
\hline Yes & $311(39.7 \%)$ & $45(51.7 \%)$ & $266(38.2 \%)$ & \\
\hline No & $473(60.3 \%)$ & $42(48.3 \%)$ & $431(61.8 \%)$ & \\
\hline Weight $(K g)^{\ddagger}$ & $\begin{array}{c}49.9 \\
(44-56)\end{array}$ & $43.8(37-50)$ & $50.7(45-56)$ & 0.000 \\
\hline CD4 count (cells/ $\mu L)^{\ddagger}$ & $\begin{array}{c}150 \\
(102-196)\end{array}$ & $72(31-99)$ & $\begin{array}{c}160 \\
(116-206)\end{array}$ & 0.000 \\
\hline Hemoglobin $(g / d L) \neq$ & $\begin{array}{c}11.4 \\
(10.0-13.0)\end{array}$ & $\begin{array}{c}9.9 \\
(7.9-11.3)\end{array}$ & $\begin{array}{c}11.6 \\
(10.3-13.1)\end{array}$ & 0.000 \\
\hline
\end{tabular}

$\ddagger$ Mean value $\left(25^{\text {th }}-75^{\text {th }}\right.$ percentile $)$

Table 2: Clinical and laboratory markers of adult PLHIV receiving ART in Somali region, Ethiopia [ $\mathrm{N}=784]$, May 2013

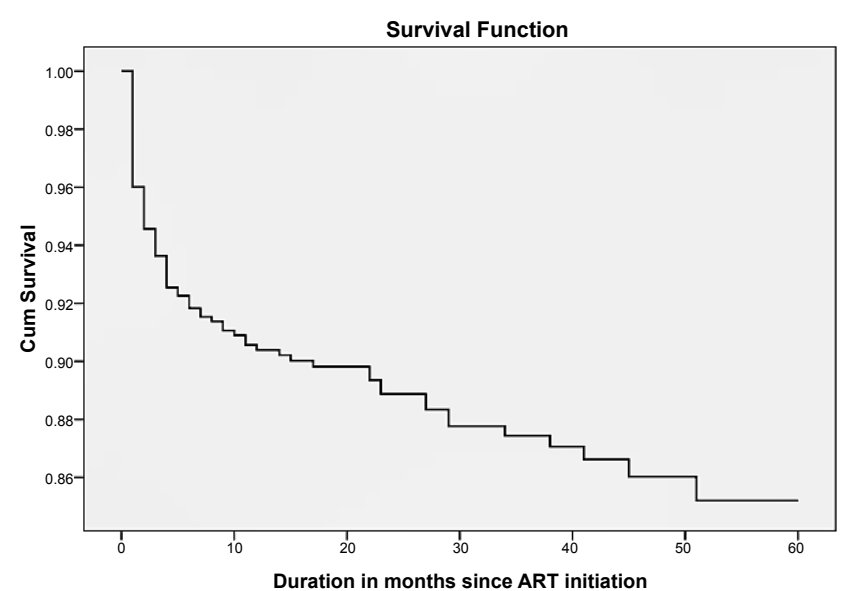

Figure 1: Cumulative survival of adult PLHIV receiving ART in Somali region, Ethiopia, May 2013.

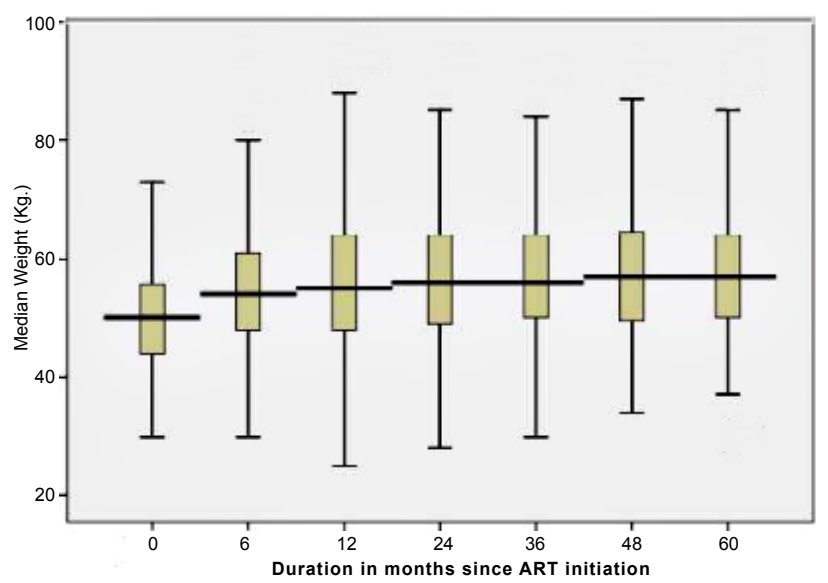

Figure 2: Median weight change during follow-up for adult PLHIV receiving ART in Somali region, Ethiopia, May 2013.

years of observation (PYO) was 5.15/100 PYO (95\% CI: 4.73-6.37). The estimated mortality was $8.4 \%, 9.8 \%, 11.3 \%, 12.7 \%$ and $14.1 \%$ at 6,12 , 24, 36 and 48 months respectively (Figure 1).

\section{Predictors of mortality}

In bivariate Cox regression analysis, sex, marital status, education level, functional status, WHO clinical stage, BMI, CD4 count, Anemia, cotrimoxazole prophylaxis, INH prophylaxis, TB co-infection, and ART adherence were all associated with survival $(\mathrm{P}<0.05)$.

In the multivariate Cox regression analysis, the independent, significant predictors of mortality in PLHIV on ART at Kharamara hospital were single marital status (AHR: 2.31; 95\%CI: 1.18-4.50), a bedridden functional status (AHR: 5.91; 95\%CI: 2.87-12.16), advanced WHO stage (AHR: 7.36; 95\%CI: 3.17-17.12), BMI $<18.5 \mathrm{Kg} / \mathrm{m}^{2}$ (AHR: 2.20; 95\%CI: 1.18-4.09), CD4 count $<50$ cells/ $\mu \mathrm{L}$ (AHR: $2.70 ; 95 \% \mathrm{CI}$ : 1.26-5.80), severe anemia (AHR: 4.57; 95\%CI: 2.30-9.10), and TB coinfection (AHR: 2.30; 95\% CI: 1.28-4.11) (Table 3).

\section{Weight and CD4 change during the follow-up}

Weight and CD4 recovery were used as supplementary indicators 
for comprehensive treatment outcomes. At the start of ART, the median weight of the cohort was $50.0 \mathrm{Kg}$. During the follow-up period, the median weight (IQR) at $6,12,24,36,48$ and 60 months were $54(48$ 61), 55 (48-64), 56 (50-64), 56 (49-64), 57 (50-65) and 57 (50-64), Kg., respectively (Figure 2). Similarly, the median CD4 count at baseline was 146 cells $/ \mu \mathrm{L}$. In the follow-up period, the median CD4 count (IQR)

\begin{tabular}{|c|c|c|c|c|}
\hline Variables & Crude HR $(95 \% \mathrm{CI})$ & $P$ value & $\operatorname{AHR}(95 \% \mathrm{CI})$ & $P$ value \\
\hline \multicolumn{5}{|l|}{ Marital status } \\
\hline Married & 1 & - & 1 & - \\
\hline Single & $2.69(1.55,4.66)$ & 0.001 & $\begin{array}{c}2.31(1.18 \\
4.50)\end{array}$ & 0.015 \\
\hline Separated & $0.40(0.05,2.94)$ & 0.367 & $\begin{array}{c}0.13(0.014 \\
1.21)\end{array}$ & 0.073 \\
\hline Divorced & $1.41(0.82,2.41)$ & 0.215 & $\begin{array}{c}1.47(0.80 \\
2.71)\end{array}$ & 0.215 \\
\hline Widowed & $1.15(0.54,2.44)$ & 0.719 & $\begin{array}{c}1.27(0.56 \\
2.86)\end{array}$ & 0.566 \\
\hline \multicolumn{5}{|c|}{ Educational status } \\
\hline No education & $5.66(1.38,23.29)$ & 0.016 & $\begin{array}{c}4.73(1.07 \\
22.40)\end{array}$ & 0.038 \\
\hline Primary & $4.26(1.01,17.91)$ & 0.048 & $\begin{array}{l}3.83(0.80 \\
18.30)\end{array}$ & 0.082 \\
\hline Secondary & $1.54(0.34,7.05)$ & 0.575 & $\begin{array}{c}2.43(0.50 \\
12.01)\end{array}$ & 0.281 \\
\hline College/Above & 1 & - & 1 & - \\
\hline \multicolumn{5}{|c|}{ Functional status } \\
\hline Working & 1 & - & 1 & - \\
\hline Ambulatory & $6.16(3.21,11.82)$ & 0.000 & $\begin{array}{c}2.12(1.05 \\
4.26)\end{array}$ & 0.035 \\
\hline Bedridden & $15.42(8.05,29.53)$ & 0.000 & $\begin{array}{c}5.91(2.87 \\
12.16)\end{array}$ & 0.000 \\
\hline \multicolumn{5}{|l|}{ WHO staging } \\
\hline Stage I\&II & 1 & - & 1 & - \\
\hline Stage III & $5.28(2.60,10.71)$ & 0.000 & $\begin{array}{c}4.00(1.83 \\
8.74)\end{array}$ & 0.000 \\
\hline Stage IV & $16.22(7.93,33.20)$ & 0.000 & $\begin{array}{c}7.36(3.17 \\
17.12)\end{array}$ & 0.000 \\
\hline \multicolumn{5}{|l|}{ BMI for age } \\
\hline$\geq 18.5 \mathrm{Kg} / \mathrm{m}^{2}$ & 1 & - & 1 & \\
\hline$<18.5 \mathrm{Kg} / \mathrm{m}^{2}$ & $2.27(1.41,3.66)$ & 0.001 & $\begin{array}{c}2.20(1.18 \\
4.09)\end{array}$ & 0.013 \\
\hline \multicolumn{5}{|l|}{ CD4 category } \\
\hline$\geq 200$ & 1 & - & 1 & - \\
\hline $125-200$ & $3.87(2.05,7.27)$ & 0.000 & $\begin{array}{c}1.33(0.65 \\
2.72)\end{array}$ & 0.440 \\
\hline $50-125$ & $5.62(3.04,10.41)$ & 0.000 & $\begin{array}{l}2.24(1.08 \\
4.65)\end{array}$ & 0.031 \\
\hline$<50$ & $17.36(9.96,30.28)$ & 0.000 & $\begin{array}{c}2.70(1.26 \\
5.80)\end{array}$ & 0.011 \\
\hline \multicolumn{5}{|l|}{ Anemia } \\
\hline Normal & 1 & - & 1 & - \\
\hline Mild & $1.16(0.56,2.42)$ & 0.695 & $\begin{array}{c}1.16(0.52 \\
2.60)\end{array}$ & 0.724 \\
\hline Moderate & $3.27(1.69,6.32)$ & 0.000 & $\begin{array}{c}2.90(1.36 \\
6.16)\end{array}$ & 0.006 \\
\hline Severe & $8.01(4.53,14.17)$ & 0.000 & $\begin{array}{c}4.57(2.30 \\
9.10)\end{array}$ & 0.000 \\
\hline \multicolumn{5}{|l|}{ TB co-infected } \\
\hline Yes & $2.21(1.35,3.62)$ & 0.002 & $\begin{array}{c}2.30(1.28 \\
4.11)\end{array}$ & 0.005 \\
\hline No & 1 & - & 1 & - \\
\hline
\end{tabular}

Table 3: Predictors of mortality among adult PLHIV receiving ART in Somali region, Ethiopia [N=784], May 2013.

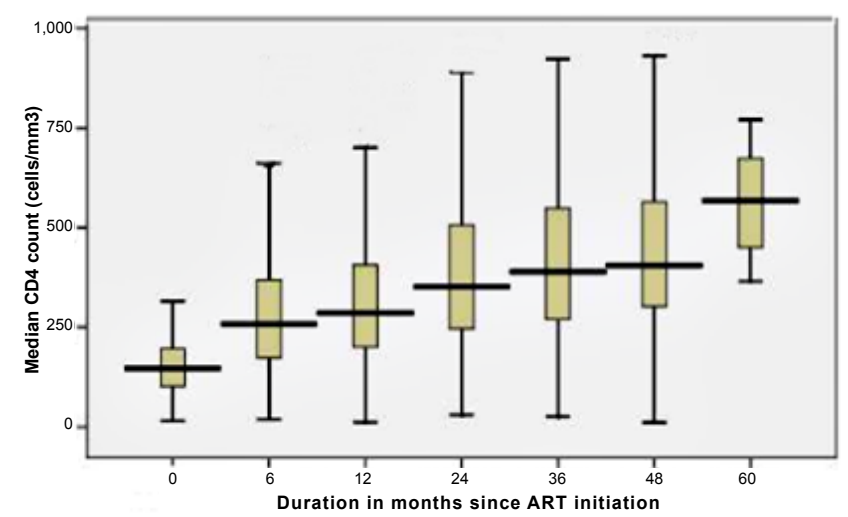

Figure 3: Median CD4 change during follow-up for adult PLHIV receiving ART in Somali region, Ethiopia, May 2013.

changed to 258 (172-369), 286 (201-406), 351 (246-506), 389 (270-549), $405(302-565)$ and $567(390-770)$ at $6,12,24,36,48$ and 60 months, respectively (Figure 3). During the follow-up period, 123 patients had their CD4 count declined to below or equal to the baseline values yielding an immunologic treatment failure rate of 7.84/100 PYO $(95 \%$ CI:6.89-8.81).

\section{Discussion}

In this historical longitudinal study, there were 87 deaths in 1,608 PYO, yielding an incidence density of 5.15/100 PYO (95\%CI: 4.73-6.37). The independent predictors of mortality include single marital status, being illiterate, bedridden functional status, advanced WHO status, low BMI, low CD4 count, severe anemia and TB co-infection. The estimated survival probability of the cohort at $6,12,24,36,48$ and 60 months was $91.6 \%, 90.2 \%, 88.7 \%, 87.3 \%, 85.9 \%$ and $84.8 \%$, respectively. This shows a better survival compared to other studies in Africa. According to a study in a Malawian cohort, the probability of being alive on ART at 6, 12 and 18 months was $89.8 \%, 83.4 \%$ and $78.8 \%$ respectively [16]. On the other hand, the death rate was comparable to most studies, especially, in the first six months $[6,8,9]$. This might be explained by the fact that most of the patients in this study had advanced disease status (78\% had CD4<200 cells/ $\mu \mathrm{L}$ and $58 \%$ were in WHO stage III \& IV).

Patients who were illiterate had high risk of mortality compared to those with college education or above (AHR: 4.73; 95\%CI: 1.07-22.40). A study conducted in Ethiopia also found a strong association between level of education and survival [17]. Single patients had a higher risk for death compared to married patients (AHR: 2.31; 95\%CI: 1.18 4.50). This difference might be due to married patients' psychological preparedness to seek partners' and social support, conceive the facts, and adhere to ART [18].

The result from this study shows patients with a CD4 count of $<50$ cells/ $\mu \mathrm{L}$ have a higher risk of mortality (AHR: 2.70; 95\% CI: 1.26-5.80) compared to those with a CD4 count of $\geq 200$ cells/ $\mu \mathrm{L}$. Majority of previous studies also found twice or more risk of mortality in patients with lower CD4 count compared to those with a CD4 count of $\geq 200$ cells/ $\mu \mathrm{L}[5,17,19]$.

Patients with severe anemia were 4.57 more at risk of death compared to those with normal levels. In a study from Tanzania, patients with severe anemia were 15 times higher at risk of dying during the first year on ART compared to those with a normal hemoglobin level [6]. Other studies have also indicated patients with low hemoglobin level 
$(<10 \mathrm{mg} / \mathrm{dL})$ had increased risk of death $[5,9,20]$. Although there is no concrete evidence on casual association between anemia and mortality, the incidence of anemia increased with progression of HIV disease [19]. In this study also, severe anemia was associated with an advanced WHO stage (24.2\% in Stage IV vs. $8.8 \%$ in stage I\&II). One of the most important side effects of AZT is myelotoxicity leading to severe anemia [20]. In this cohort, severe anemia in patients taking AZT was higher (46.7\%) among the dead compared to those censored (8.8\%).

In the current study, the risk of death in patients with a $\mathrm{BMI}<18.5$ $\mathrm{Kg} / \mathrm{m}^{2}$ was more than two times higher (AHR: 2.20 ; 95\%CI: $1.18-4.09$ ) compared to those with a BMI $\geq 18.5 \mathrm{~kg} / \mathrm{m}^{2}$. Study conducted in rural Malawi showed individuals who were severely malnourished $(\mathrm{BMI}<16$ $\mathrm{kg} / \mathrm{m}^{2}$ ) had six times higher risk of dying in the first three months than those with a normal nutritional status [21]. BMI is an indicator of patient nutritional status but may also be influenced by late-stage AIDS conditions, such as wasting syndrome and opportunistic infections, or by progression of the HIV itself [22]. In the current cohort, there was a significant difference in mean BMI between TB positive patients (18.10; 95\%CI: 17.66-18.54) and TB negative ones (18.77; 95\%CI: 18.40-19.14), and also, between WHO stage I\&II (19.68; 95\%CI: 19.24-20.13) and WHO stage IV (17.13; 95\%CI: 16.49-17.77).

TB co-infection at baseline or later was also associated with increased risk of mortality (AHR: 2.30; 95\%CI: 1.28-4.11). Study conducted in Uganda shows, after adjusting for a history of HIV related infections, the overall relative hazard for death associated with tuberculosis was 1.81 (95\%CI: 1.24-2.65) [23]. Manosuthi et al. also showed patients who delayed ART for $>6$ months after TB diagnosis had a higher mortality rate than those who initiated ART $<6$ months after TB diagnosis [24]. Other studies in Ethiopia have also showed the similar relationship $[10,25]$. High mortality in patients living with HIV/ AIDS in poor countries was linked to concomitant TB infection [20]. This may be because TB is the leading cause of death worldwide, and the virulence of the mycobacterium increases in HIV infected patients, where the host's immune system is suppressed, enabling it to establish infection very easily [26].

Different studies conducted in African countries, including Ethiopia, have shown a progressive change in CD4 count and weight after initiation of ART $[9,27]$. These studies showed that the most significant increment in the median CD4 count occurred in the first six months of ART which is also the case in the current study; wherein a $76.2 \%$ increase from baseline median level was observed in the first six months. The recovery in weight also showed a similar progress in the first six months (8\% gains). However, the change in median CD4 and median weight in subsequent months was minimal, with an average gain of $17 \%$ and $1.4 \%$, respectively. In addition, the immunologic recovery was much slower in patients with baseline AIDS defining disease [23].

This cohort study has provided information on prognostic factors for death in adult PLHIV receiving ART. The findings can be essential inputs in redesigning clinical management of high risk patients and ultimately improving their survival and quality of living. In addition, this study will provide ample information for future, more focused, prospective studies, especially on outcome status and underlying causes of patients lost to follow-up.

\section{Limitations of the Study}

The study has few limitations. Inclusion of only patients with complete records of baseline information during data collection might have made selection bias possible.As data used in this study was retrospective, there were few incomplete follow-up records (due to patients' missed clinical visits), and we were unable to include some variables (e.g. CD4, Hgb, etc.) as time-dependent covariates in our analysis.All deaths were considered as AIDS related for lack of available records on the causes of death.

\section{Conclusion}

Improved survival was observed in patients taking ART in Somali region of Ethiopia. However, the risk for death was higher in patients with bed-ridden functional status, advanced WHO stage, low CD4 count, severe anemia, low BMI, and concomitant TB infection. Intensive clinical and nutritional rehabilitation is recommended during the earliest follow up periods on ART for patients with these prognostic factors. Providing follow-up screening and chemoprophylaxis for to patients with a history of TB infection on ART is insurmountable in deterring the infection and decreasing mortality. Optimal immunologic and weight recoveries occurred in the first six months indicating the need for increased attention and clinical management for patients with higher risk for death during this crucial period of recovery.

\section{Acknowledgements}

We would like to thank and appreciate all patients who participated in the study. We are indebted to the staff at Kharamara hospital ART clinic, especially, Azenegash Mekonen and Samrawit Mekonen for their invaluable contributions in collection and quality control of data. We are grateful to the adherence supporters Abun Dube and Aynalem Bekele who carried out home visits to ascertain patients final outcome status. We are also grateful to Somali Regional Health Bureau for facilitating conditions while carrying out this study. We would like to extend our heartfelt gratitude and appreciations to Tiringo Nigusse for her financial support to this project.

\section{References}

1. UNAIDS (2012) Global report: UNAIDS report on the global AIDS epidemic 2012. Joint United Nations Programme on HIVIAIDS (UNAIDS), Geneva.

2. HAPCO (2012) HIVIAIDS Estimates and Projections in Ethiopia, 2011-2016 Federal HIVIAIDS Prevention and Control Office, Addis Ababa, Ethiopia.

3. CSA \& ICF Macro (2011) Ethiopia Demographic and Health Survey. Centra statistics Agency (CSA), Addis Ababa.

4. FMoH/HAPCO (2012) Country Progress Report on HIVIAIDS Response. Addis Ababa, Ethiopia.

5. Ojikutu BO, Zheng H, Walensky RP, Lu Z, Losina E, et al. (2008) Predictors of mortality in patients initiating antiretroviral therapy in Durban, South Africa. S Afr Med J 98: 204-208.

6. Johannessen A, Naman E, Ngowi BJ, Sandvik L, Matee MI, et al. (2008) Predictors of mortality in HIV-infected patients starting antiretroviral therapy in a rural hospital in Tanzania. BMC Infect Dis 8: 52.

7. Boerma JT, Stanecki KA, Newell ML, Luo C, Beusenberg M, et al. (2006) Monitoring the scale-up of antiretroviral therapy programmes: methods to estimate coverage. Bull World Health Organ 84: 145-150

8. Jerene D, Endale A, Hailu Y, Lindtjørn B (2006) Predictors of early death in a cohort of Ethiopian patients treated with HAART. BMC Infect Dis 6: 136.

9. Alemu AW, Sebastián MS (2010) Determinants of survival in adult HIV patients on antiretroviral therapy in Oromiyaa, Ethiopia. Glob Health Action 3.

10. Jerene D, Naess A, Lindtjørn B (2006) Antiretroviral therapy at a district hospital in Ethiopia prevents death and tuberculosis in a cohort of HIV patients. AIDS Res Ther 3: 10.

11. FDRE-MoH (2012) Guidelines for Clinical and Programmatic Management of TB, Leprosy and TB/HIV In Ethiopia. Federal Ministry of Health 5th Ed.

12. FMoH (2007) Implementation Guideline for TB/HIV Collaborative Activities in Ethiopia. Federal Ministry of Health.

13. FMoH/HAPCO (2008) Guidelines for Management of Opportunistic Infections and Antiretroviral treatment in adolescents and adults in Ethiopia. Federa Ministry of Health.

14. Ferro-Luzzi A, Sette S, Franklin M, James WP (1992) A simplified approach of assessing adult chronic energy deficiency. Eur J Clin Nutr 46: 173-186. 
Citation: Damtew B, Mengistie B, Alemayehu T (2014) Survival and Determinants of Mortality in Adult HIV/AIDS Patients Initiating Antiretroviral Therapy in Somali Region, Eastern Ethiopia. J AIDS Clin Res 5: 327. doi:10.4172/2155-6113.1000327

15. WHO (2001) Iron Deficiency Anemia: Assessment, Prevention, and Control. A guide for program managers.

16. Banda AC, Makombe SD, Jahn A, Tweya H, Chuka S, et al. (2008) Antiretroviral therapy in the Malawi defence force: access, treatment outcomes and impact on mortality. PLoS One 3: e1445.

17. Biadgilign S, Reda AA, Digaffe T (2012) Predictors of mortality among HIV infected patients taking antiretroviral treatment in Ethiopia: a retrospective cohort study. AIDS Res Ther 9: 15.

18. Auld AF, Mbofana F, Shiraishi RW, Sanchez M, Alfredo C, et al. (2011) Fouryear treatment outcomes of adult patients enrolled in Mozambique's rapidly expanding antiretroviral therapy program. PLoS One 6: e18453.

19. Johansson KA, Robberstad B, Norheim OF (2010) Further benefits by early start of HIV treatment in low income countries: survival estimates of early versus deferred antiretroviral therapy. AIDS Res Ther 7: 3.

20. Canestri A, Sow PS, Vray M, Ngom F, M'boup S, et al. (2007) Poor Efficacy and Tolerability of Stavudine, Didanosine, and Efavirenz-based Regimen in Treatment-Naive Patients in Senegal. Med Gen Med 9:7.

21. Zachariah R, Fitzgerald M, Massaquoi M, Pasulani O, Arnould L, et al. (2006) Risk factors for high early mortality in patients on antiretroviral treatment in a rural district of Malawi. AIDS 20: 2355-2360.
22. van der Sande MA, Schim van der Loeff MF, Aveika AA, Sabally S, Togun T, et al. (2004) Body mass index at time of HIV diagnosis: a strong and independent predictor of survival. J Acquir Immune Defic Syndr 37: 1288-1294.

23. Kigozi BK, Sumba S, Mudyope P, Namuddu B, Kalyango J, et al. (2009) The effect of AIDS defining conditions on immunological recovery among patients initiating antiretroviral therapy at Joint Clinical Research Centre, Uganda. AIDS Research and Therapy 6: 1-10.

24. Manosuthi W, Chottanapand S, Thongyen S, Chaovavanich A, Sungkanuparph $S$ (2006) Survival rate and risk factors of mortality among HIV/tuberculosiscoinfected patients with and without antiretroviral therapy. J Acquir Immune Defic Syndr 43: 42-46

25. Eyuel T, Alemayehu W (2001) Assessment of antiretroviral treatment outcome in public hospitals, South Nations Nationalities and Peoples Region, Ethiopia. Ethiop J Health Dev 25: 102-109.

26. Khan FA, Minion J, Pai M, Royce S, Burman W, et al. (2010) Treatment of active tuberculosis in HIV-coinfected patients: a systematic review and metaanalysis. Clin Infect Dis 50: 1288-1299.

27. Lawn SD, Myer L, Bekker LG, Wood R (2006) CD4 cell count recovery among HIV-infected patients with very advanced immunodeficiency commencing antiretroviral treatment in sub-Saharan Africa. BMC Infect Dis 6: 59. 